\title{
Article \\ Rapid Formation of Nanoclusters for Detection of Drugs in Urine Using Surface-Enhanced Raman Spectroscopy
}

\author{
Yun-Chu Chen ${ }^{1}$, Shang-Wen Hong ${ }^{1}$, Huang-Hesin Wu ${ }^{1}$, Yuh-Lin Wang ${ }^{2} \mathbb{D}$ and Yih-Fan Chen ${ }^{1, *}(\mathbb{D}$ \\ 1 Institute of Biophotonics, National Yang Ming Chiao Tung University, Taipei 112, Taiwan; \\ yunchu00@gmail.com (Y.-C.C.); joy0970515997@gmail.com (S.-W.H.); leowu0719@gmail.com (H.-H.W.) \\ 2 Institute of Atomic and Molecular Sciences, Academia Sinica, Taipei 106, Taiwan; \\ ylwang@pub.iams.sinica.edu.tw \\ * Correspondence: chenyf@nycu.edu.tw
}

Citation: Chen, Y.-C.; Hong, S.-W.; Wu, H.-H.; Wang, Y.-L.; Chen, Y.-F. Rapid Formation of Nanoclusters for Detection of Drugs in Urine Using Surface-Enhanced Raman Spectroscopy. Nanomaterials 2021, 11, 1789. https:// doi.org/10.3390/nano11071789

Academic Editors: Mohsen Rahmani, Cuifeng Ying and Lei $\mathrm{Xu}$

Received: 9 June 2021

Accepted: 7 July 2021

Published: 9 July 2021

Publisher's Note: MDPI stays neutral with regard to jurisdictional claims in published maps and institutional affiliations.

Copyright: (c) 2021 by the authors. Licensee MDPI, Basel, Switzerland. This article is an open access article distributed under the terms and conditions of the Creative Commons Attribution (CC BY) license (https:/ / creativecommons.org/licenses/by/ $4.0 /)$.

\begin{abstract}
We developed a method based on surface-enhanced Raman spectroscopy (SERS) and a sample pretreatment process for rapid, sensitive, reproducible, multiplexed, and low-cost detection of illegal drugs in urine. The abuse of new psychoactive substances (NPS) has become an increasingly serious problem in many countries. However, immunoassay-based screening kits for NPS are usually not available because of the lack of corresponding antibodies. SERS has a great potential for rapid detection of NPS because it can simultaneously detect multiple kinds of drugs without the use of antibodies. To achieve highly sensitive SERS detection of drugs, sodium bromide was first employed to induce the rapid formation of Ag nanoclusters by aggregating silver nanoparticles (AgNPs) in the extracted sample solution. SERS measurements were performed immediately after the sample pretreatment without incubation. The three-dimensional SERS hot spots were believed to form significantly within the nanoclusters, providing strong SERS enhancement effects. The displacement of citrate molecules on the surfaces of the AgNPs by bromide ions helped increase the adsorption of drug molecules, increasing their areal density. We demonstrated the simultaneous detection of two kinds of NPS, methcathinone and 4-methylmethcathinone, in urine at a concentration as low as $0.01 \mathrm{ppm}$.
\end{abstract}

Keywords: surface-enhanced Raman spectroscopy (SERS); drug; new psychoactive substance; urine; nanocluster

\section{Introduction}

Drug abuse has become an increasingly serious problem in many countries. The use of either traditional illegal drugs such as cocaine and heroin or new psychoactive substances (NPS) such as methcathinone (MC) and 4-methylmethcathinone (4-MMC, mephedrone) poses a serious threat to health and public security. To detect the use of illegal drugs during the preceding 1-4 days, urine samples are usually collected and analyzed using GC-MS or LC-MS/MS [1-3]. These methods can provide sensitive and specific detection of drugs; however, they need to be performed by well-trained personnel in a laboratory and require delicate sample pretreatment processes and expensive reagents. Therefore, for the rapid, on-site detection of illegal drugs, lateral flow immunoassays are usually used instead [4,5]. These assays are low-cost and easy-to-use, but they usually suffer from a higher falsepositive rate [4]. Rapid screening of NPS is especially difficult because immunoassay test kits are usually not available due to the lack of corresponding antibodies and aptamers. Therefore, to prevent the spread of NPS, the development of a rapid, simple, sensitive, and low-cost method that can detect NPS in urine without the need of antibodies or aptamers is urgent.

Surface-enhanced Raman spectroscopy (SERS) has been used to detect a variety of molecules [6-10] because SERS-based methods only need a small sample and take a few seconds to achieve the multiplexed detection of molecules with high sensitivity. Many studies 
have reported the SERS detection of drugs, including cannabinoid [11], cocaine [12-17], flunitrazepam [18], alpha-methyltryptamine [19], heroin [17,20], ketamine [21], morphine [13,22], benzodiazepine [23], methamphetamine [13,24-30], amphetamine [31], opioid [32], 3,4methylenedioxymethamphetamine (MDMA) [25,27,28,33], 4-MMC [34,35], MC [25], barbiturate [36], and sulfa drugs [37]. While the plasmonic properties of nanostructured substrates or nanoparticles used for SERS measurements is critical for the sensitive detection of molecules, it has been demonstrated that sample pretreatment is also very important for the SERS detection of drugs in biological samples such as urine $[14,25,27,29,30,36]$ and serum [30]. It should be noted that, although antibodies or aptamers are sometimes used in SERS-based detection methods [12], they are not required in all SERS detection methods, which makes it useful for detecting NPS.

Three-dimensional (3D) SERS substrates have drawn much attention in recent years [38]. Given that the laser focal volume is a 3D space, SERS substrates with SERS hot spots in all spatial directions can utilize the laser focal volume better than a 2D SERS substrate. In addition, having SERS hot spots in the z-axis allows for a higher tolerance for the position of the laser focal plane. Recent studies showed that 3D SERS substrates could be fabricated using nano-fabrication processes [39] or formed by metal colloidal nanoparticles [19,27,40-43]. For example, several studies demonstrated that a 3D SERS hot spot matrix could be formed by evaporating a droplet of metal nanoparticles to provide highly sensitive detection of molecules $[19,40-43]$. As the interparticle distance, which was critical to the SERS effect, gradually decreased during the evaporation process in those studies, the interparticle distance could decrease to an optimal value at a certain time point and resulted in strong SERS effects. On the other hand, instead of using the evaporation process, inducing the aggregation of nanoparticles was another strategy to generate 3D SERS hot spots [32,44]. The sensitive and quantitative SERS detection of molecules was demonstrated by adding a suitable kind and concentration of aggregating agent, such as an alkali halide salt [32,45], to colloidal metal nanoparticles to form nanoclusters with many SERS-active nanogaps.

In this study, we developed a sensitive and reproducible SERS method for the detection of drugs in urine. A simple sample pretreatment process was developed to reduce interferences from other components in urine on the detection results. An SERS measurement was performed immediately after sodium bromide ( $\mathrm{NaBr}$ ), a kind of alkali halide salt, was added to a mixture of the pretreated sample and a silver nanoparticle (AgNP) colloidal solution. By using an alkali halide salt as an aggregating agent to induce the rapid formation of Ag nanoclusters with SERS hot spots in three dimensions, the sensitive and reproducible detection of drugs was achieved without incubation time and a nanofabricated SERS substrate. We demonstrated individual and simultaneous detection of two kinds of NPS, MC and 4-MMC, in urine at a concentration as low as $0.01 \mathrm{ppm}$.

\section{Materials and Methods}

\subsection{Materials}

$\mathrm{S}(-)$-methcathinone hydrochloride solution, 4-methylmethcathinone (mephedrone) hydrochloride solution, $\mathrm{n}$-hexane, sodium chloride $(\mathrm{NaCl})$, potassium bromide $(\mathrm{KBr})$, and sodium borohydride $\left(\mathrm{NaBH}_{4}\right)$ were purchased from Sigma-Aldrich. Sodium bromide $(\mathrm{NaBr})$ and silver nitrate $\left(\mathrm{AgNO}_{3}\right)$ were purchased from J.T. Baker. Trisodium citrate dihydrate and sodium hydroxide $(\mathrm{NaOH})$ were purchased from Showa Chemical Industry. Ultrapure water was produced by a Millipore water system.

\subsection{Synthesis of $A g N P s$}

The glassware used for the synthesis of AgNPs was cleaned with aqua regia and was then rinsed with ultrapure water before use. To synthesize 4-nanometer AgNP seeds, $47.5 \mathrm{~mL}$ of $0.2 \%$ trisodium citrate, $0.85 \mathrm{~mL}$ of $60 \mathrm{mM} \mathrm{AgNO}_{3}$, and $1 \mathrm{~mL}$ of $0.1 \% \mathrm{NaBH}_{4}$ were mixed at $70{ }^{\circ} \mathrm{C}$ in a reflux setup for $60 \mathrm{~min}$. Next, to increase the size of the AgNPs, $5 \mathrm{~mL}$ of the synthesized 4-nanometer AgNP seeds, $1 \mathrm{~mL}$ of $1 \%$ trisodium citrate, $37.5 \mathrm{~mL}$ of ultrapure water, and $0.85 \mathrm{~mL}$ of $60 \mathrm{mM} \mathrm{AgNO}_{3}$ were mixed and boiled in a reflux 
setup for $60 \mathrm{~min}$. Then, $1 \mathrm{~mL}$ of $1 \%$ trisodium citrate and $0.85 \mathrm{~mL}$ of $60 \mathrm{mM} \mathrm{AgNO}$ were added to the boiled mixture, and the mixture was boiled for another $60 \mathrm{~min}$. The addition of trisodium citrate and $\mathrm{AgNO}_{3}$ and the boiling process were repeated two more times. Finally, the mixture was cooled to room temperature, and the AgNPs were ready to use. Transmission electron microscopy (TEM) images showed that the diameter of the AgNPs was $\sim 28 \mathrm{~nm}$. (Supplementary material Figure S1a). The localized surface plasmon resonance (LSPR) wavelengths of the 4-nanometer AgNP seeds and the 28-nanometer AgNPs were $391.9 \mathrm{~nm}$ and $395.1 \mathrm{~nm}$, respectively (Supplementary material Figure S1b).

\subsection{Urine Sample Pretreatment}

The sample pretreatment process, which was modified from a process reported in the literature [25], is illustrated in Scheme 1. Briefly, human urine $(1 \mathrm{~mL})$ was mixed with $0.68 \mathrm{~g}$ of $\mathrm{NaCl}$ and $200 \mu \mathrm{L}$ of $5 \% \mathrm{NaOH}$ for $30 \mathrm{~s}$. Then, n-hexane $(200 \mu \mathrm{L})$ was added to the mixture, and the mixture was vigorously mixed by a vortex mixer for $30 \mathrm{~s}$. After the mixing, the mixture was centrifuged at $9500 \mathrm{~g}$ for $2 \mathrm{~min}$, and then the upper organic phase was transferred to another centrifuge tube. Finally, the collected n-hexane solution was dried at $70{ }^{\circ} \mathrm{C}$, and ultrapure water $(10 \mu \mathrm{L})$ was added to the centrifuge tube to resuspend the extracted drugs for SERS measurements.

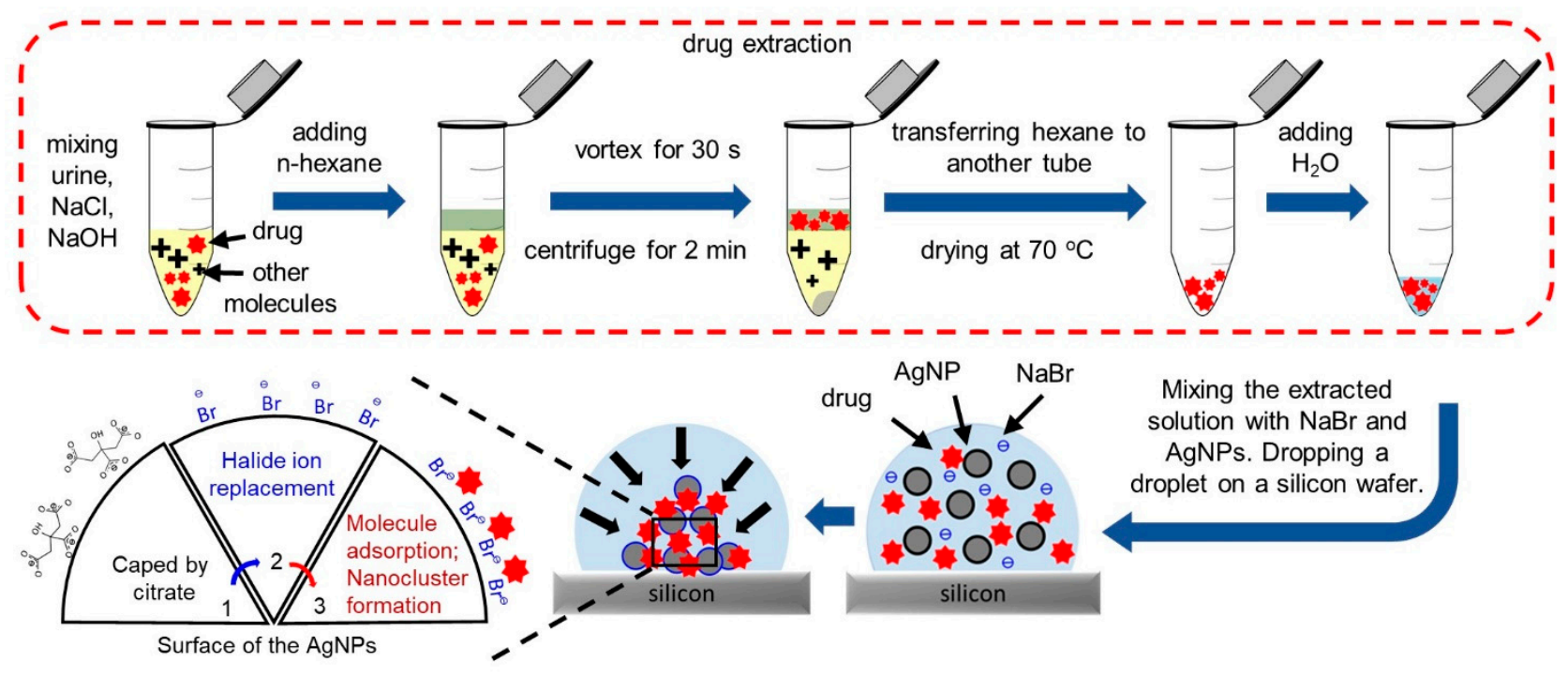

Scheme 1. Illustration of the urine sample pretreatment and the formation of Ag nanoclusters for SERS detection of drugs in urine. A human urine sample is mixed with $\mathrm{NaCl}, \mathrm{NaOH}$, and n-hexane for drug extraction. $\mathrm{NaBr}$ was added to the extracted solution to induce rapid formation of Ag nanoclusters and to increase the adsorption of molecules on the AgNPs for SERS detection of drugs. A droplet of the mixture of AgNPs, $\mathrm{NaBr}$, and the extracted sample solution was dropped onto a silicon wafer for SERS measurements.

\subsection{SERS Measurement}

To induce the rapid formation of Ag nanoclusters for SERS measurements, $0.5 \mu \mathrm{L}$ of $250 \mathrm{mM} \mathrm{NaBr}$ was mixed with $5 \mu \mathrm{L}$ of the synthesized $28 \mathrm{~nm}$ AgNPs and $5 \mu \mathrm{L}$ of the sample solution (standard solution or extracted urine sample). The final concentration of $\mathrm{NaBr}$ in the mixture was $\sim 12 \mathrm{mM}$. After the mixing, $5 \mu \mathrm{L}$ of the mixture was dropped onto a silicon wafer for measurements. A 532-nanometer-Raman system (B\&W TEK, i-Raman-532S) was used to measure the SERS spectra. The laser from the Raman probe was directed into a side port of an upright microscope (Olympus, BX51) and was focused by a 20X objective lens (N.A. 0.7) on a droplet of the mixture during SERS measurements. 


\section{Results and Discussion}

\subsection{Formation of SERS-Active Nanoclusters}

The sample pretreatment and measurement processes for the SERS detection of drugs in urine are shown in Scheme 1. To extract drugs from urine, hexane and a large amount of $\mathrm{NaCl}$ were added to the samples first. $\mathrm{NaCl}$ was used to reduce the solubility of the drugs, and hexane was used to extract the drugs from the urine. After shaking the mixture of urine and hexane vigorously for $30 \mathrm{~s}$, the upper phase containing hexane and the extracted drugs was transferred to another microcentrifuge tube and was then dried by heating. Finally, a small amount of water was added to the microcentrifuge tube to obtain a concentrated, resuspend drug solution for measurement. The whole sample pretreatment process could be finished within $20 \mathrm{~min}$.

To detect drugs using SERS, an alkali halide salt, which functioned as an aggregating agent, and AgNPs were added to a sample solution before the SERS measurements. It has been known that alkali halide ions can replace citrate molecules on the surfaces of AgNPs and reduce the stability of colloidal nanoparticles [32]. Depending on the kind and the concentration of the alkali halide salt mixed with the AgNPs, the AgNPs may form many small nanoclusters or large aggregates. However, for sensitive SERS detection of molecules, small nanoclusters are generally preferred over large aggregates because the molecules of interest can access the nanogaps among nanoparticles more easily. To find a suitable kind and concentration of alkali halide salt to induce the formation of nanoclusters for SERS detection, we measured 1 ppm MC using three kinds of alkali halide salts, $\mathrm{NaCl}$, $\mathrm{NaBr}$, and $\mathrm{KBr}$, with different concentrations, as shown in Figure $1 \mathrm{a}, \mathrm{c}, \mathrm{e}$. The range of the concentrations tested was different for the three kinds of alkali halide salts because they had different effects on the stability of the AgNPs. For each SERS measurement, we quickly mixed the drug solution, the 28-nanometer AgNPs, and one of the kinds of alkali halide salt, and then put a droplet of the mixture on a silicon wafer. The SERS spectra were measured immediately after the mixing without incubation. The droplet was not covered by a coverslip, and the 532-nanometer laser of the Raman system was focused on the droplet for measuring the SERS spectra. Figure $1 \mathrm{~b}, \mathrm{~d}$,f show that the intensity of the characteristic Raman peak of MC at $1000 \mathrm{~cm}^{-1}$ varied with the kind and the concentration of the alkali halide salt. Among the nine experimental conditions tested, we found that the intensity of the $1000 \mathrm{~cm}^{-1}$ peak was highest when $12 \mathrm{mM} \mathrm{NaBr}$ was mixed with the AgNPs and the sample solution. Therefore, we used this amount of $\mathrm{NaBr}$ to induce the formation of Ag nanoclusters for the other experiments of this study.

The rapid formation of nanoclusters in a sample solution allowed us to detect molecules using SERS without incubation time. According to the extinction spectra of the AgNPs, the LSPR peak of the AgNP solution increased from 395.1 to $399.7 \mathrm{~nm}$ right after the addition of $\mathrm{NaBr}$ but then remained almost unchanged afterwards (Supplementary material Figure S1c,d). The dynamic light scattering (DLS) measurements also showed that the addition of $\mathrm{NaBr}$ caused an increase in the hydrodynamic diameter of the AgNPs (Supplementary material Figure S2a,b). Both the red shift in the LSPR peak and the increase in the hydrodynamic diameter indicated the formation of nanoclusters. A time-lapse observation of the SERS spectra of $1 \mathrm{ppm}$ MC after the addition of $12 \mathrm{mM} \mathrm{NaBr}$ showed a slight increase in the Raman signal over time (Supplementary material Figure S3), which was likely caused by the evaporation-induced concentration of molecules. As the rate of evaporation depends on several factors, such as the humidity and temperature of the surrounding environment, to avoid the effect of evaporation on the detection, we performed the SERS measurements immediately after we put a droplet of the sample on a silicon wafer.

It should be noted that mixing the AgNPs with $\mathrm{NaBr}$ also helped to increase the adsorption of the drug molecules to the AgNPs because the citrate molecules capped on the surfaces of the AgNPs were displaced with bromide ions [32]. The Raman signals of the drug molecules adsorbed on the AgNPs could be significantly enhanced because of the SERS effects of the nanoclusters. On the other hand, the intensity of the characteristic Raman peak of citrate molecules at $\sim 1400 \mathrm{~cm}^{-1}$ was not very strong in the measured 
spectra. It was most likely because the majority of the citrate molecules on the surfaces of the AgNPs were displaced by bromide ions during the displacement and aggregation processes that led to the formation of SERS hot spots.

(a)

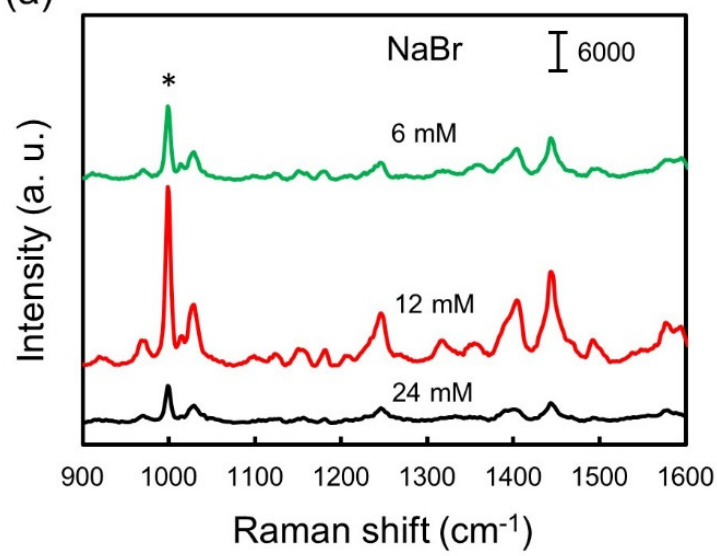

(c)

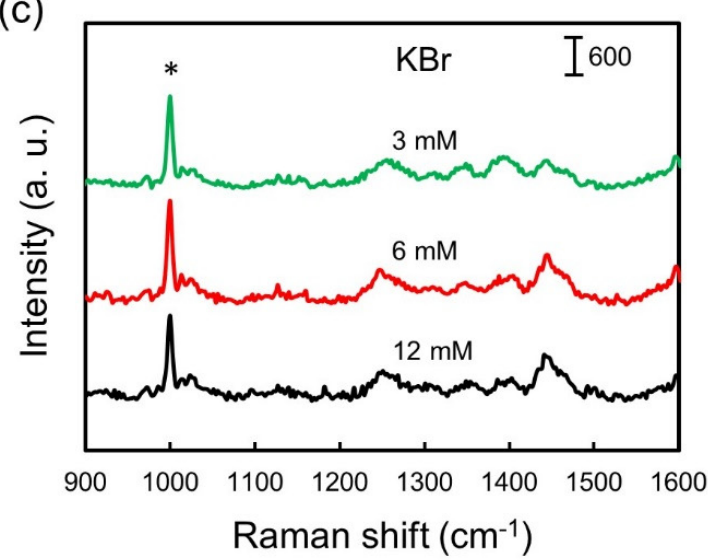

(e)

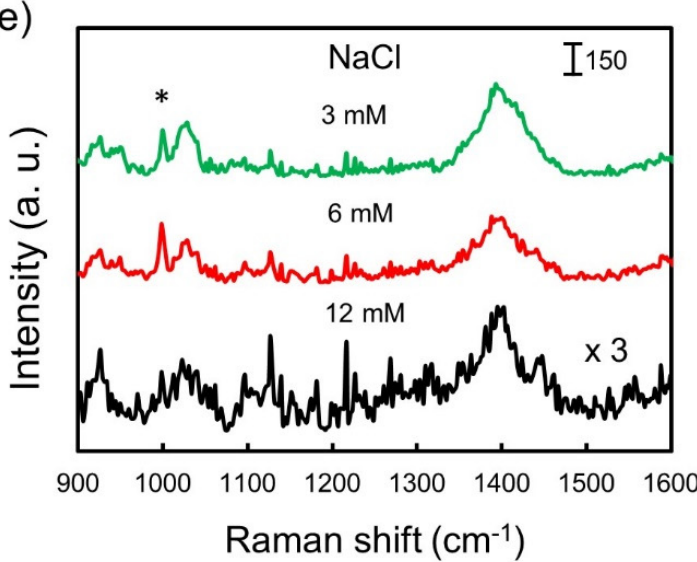

(b)

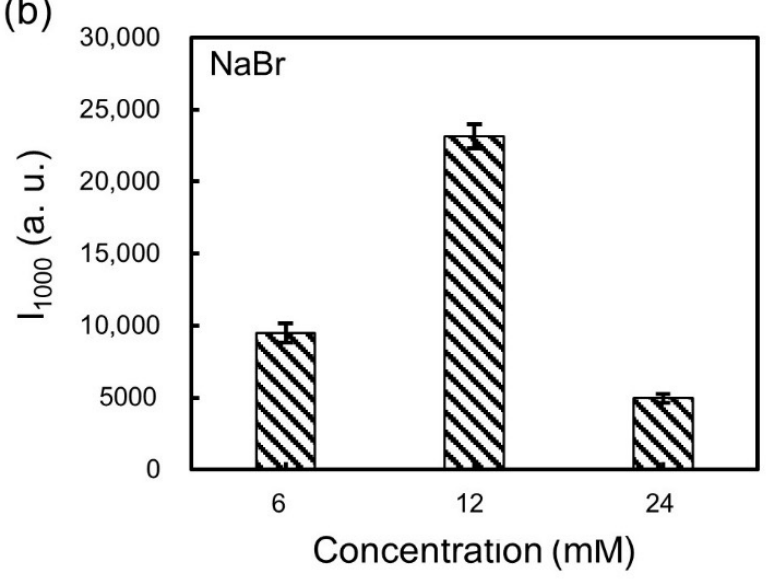

(d)

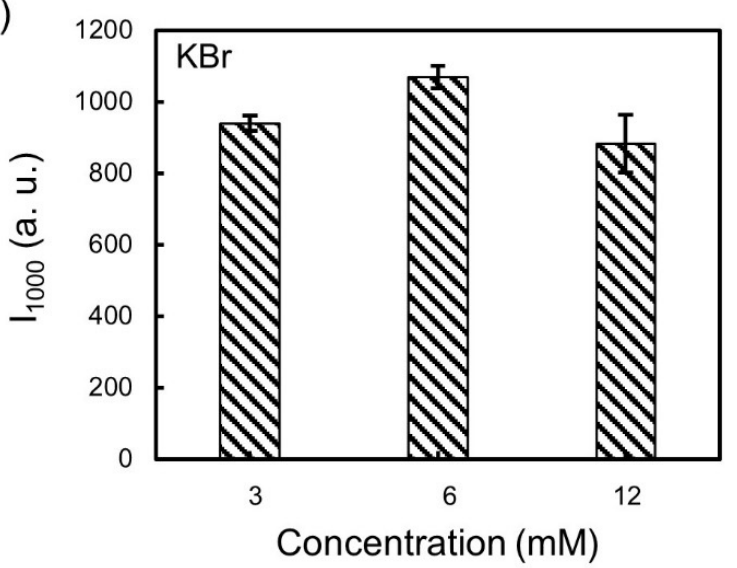

(f)

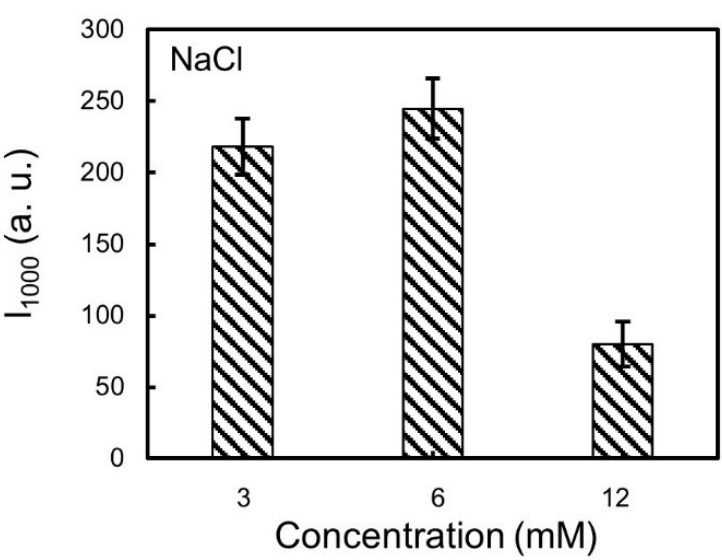

Figure 1. Effects of the kind and the concentration of alkali halide salt on SERS detection of drugs. (a,c,e) SERS spectra of 1 ppm MC standard solution measured using the nanoclusters induced by (a) $\mathrm{NaBr}$, (b) $\mathrm{KBr}$, and (c) $\mathrm{NaCl}$ of different concentrations. The characteristic Raman peak of MC at $1000 \mathrm{~cm}^{-1}$ is marked with "*". (b,d,f) The intensities of the characteristic Raman peak of MC at $1000 \mathrm{~cm}^{-1}$ measured using the nanostructures induced by (b) $\mathrm{NaBr}$, (d) $\mathrm{KBr}$, and (f) $\mathrm{NaCl}$ of different concentrations. Error bars show standard deviations with $\mathrm{n}=30$. 


\subsection{Detection of $M C$ and 4-MMC in Water}

After finding the suitable kind and concentration of the aggregating agent, we used the optimal experimental condition to measure MC and 4-MMC standard solutions of different concentrations. Figure 2a shows the SERS spectra of MC with a concentration between 0.01 and $1 \mathrm{ppm}$, and Figure $2 \mathrm{~b}$ shows the relationship between the concentration of MC and the intensity of the characteristic Raman peak at $1000 \mathrm{~cm}^{-1}$. Similarly, Figure $2 \mathrm{c}$ shows the SERS spectra of 4-MMC with a concentration between 0.01 and $1 \mathrm{ppm}$, and Figure $2 \mathrm{~d}$ shows the relationships between the concentration of 4-MMC and the intensities of the three characteristic Raman peaks at 799, 970, $1212 \mathrm{~cm}^{-1}$, respectively. Our results showed that MC and 4-MMC could be detected within $1 \mathrm{~min}$ with high sensitivity using the SERS method developed in this study.

(a)

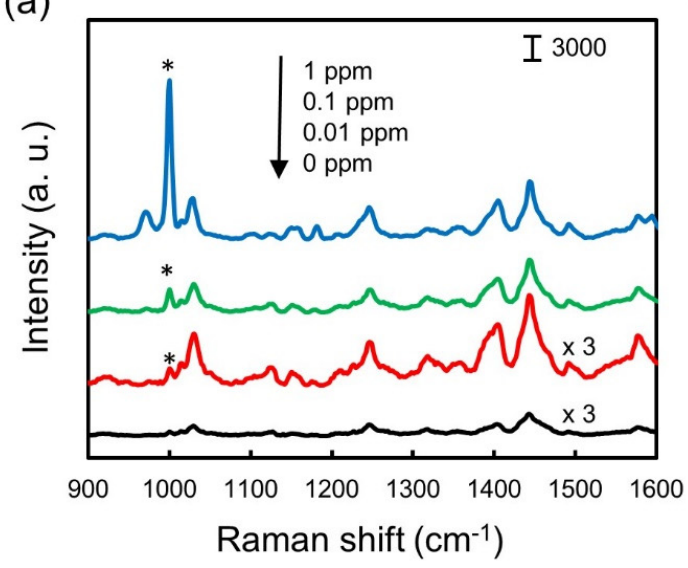

(c)

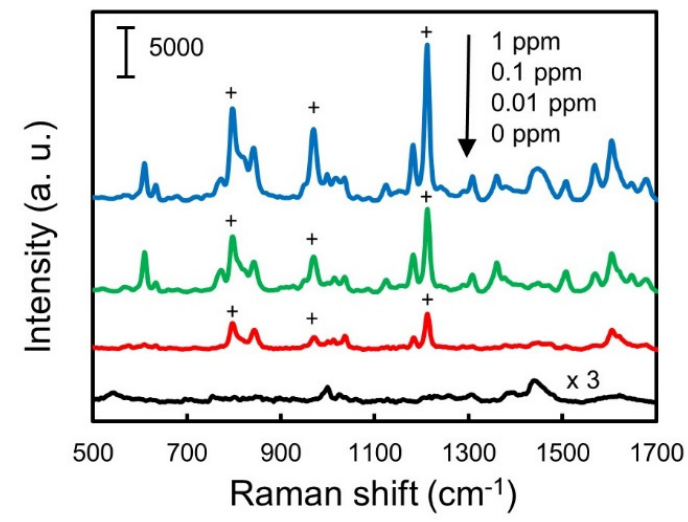

(b)

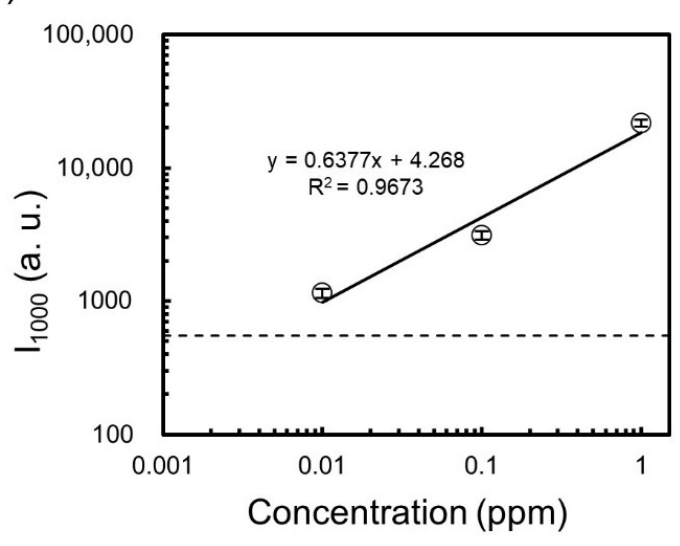

(d)

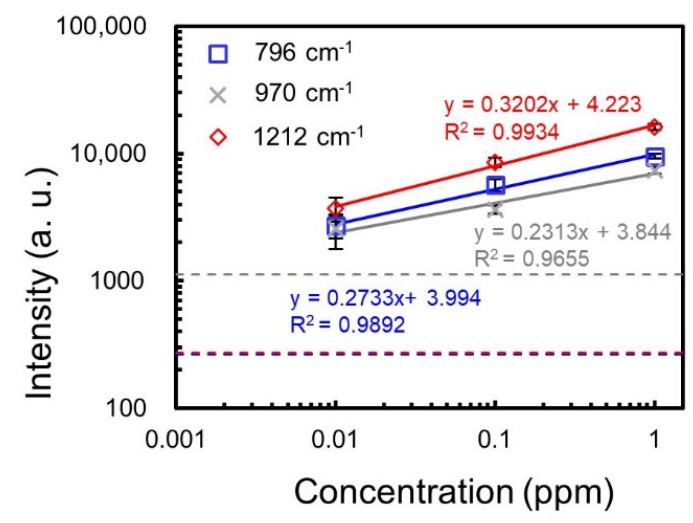

Figure 2. SERS detection of MC and 4-MMC in water. (a,c) SERS spectra of (a) MC and (c) 4-MMC in water with concentrations ranging from 0.01 to $1 \mathrm{ppm}$. The characteristic Raman peak of MC at $1000 \mathrm{~cm}^{-1}$ and the characteristic Raman peak of 4-MMC at $1212 \mathrm{~cm}^{-1}$ are marked with "**" and "+", respectively. (b) A plot of the intensity of the $1000 \mathrm{~cm}^{-1}$ peak versus MC concentration. Error bars show standard deviations with $n=30$. The straight line is the linear regression line, and the dotted line indicates mean plus 3 standard deviations (mean $+3 \sigma, \sigma$ is the standard deviation) of the $1000 \mathrm{~cm}^{-1}$ peak of the blank sample. (d) A plot of the intensities of the 796, the 970, and the $1212 \mathrm{~cm}^{-1}$ peaks versus 4-MMC concentration. Error bars show standard deviations with $\mathrm{n}=30$. The straight lines are the linear regression lines, and the blue, gray, and red dotted lines indicate mean plus $3 \sigma$ of the 796 , the 970 , and the $1212 \mathrm{~cm}^{-1}$ peaks, respectively, of the blank sample.

\subsection{Simultaneous Detection of MC and 4-MMC in Water}

In addition to demonstrating the SERS detection of each of the two kinds of drugs, we also tested the simultaneous detection of both MC and 4-MMC. Compared with immunoassay methods, simultaneous detection of multiple kinds of drugs is an advantage for 
SERS-based method because it does not require multiple kinds of antibodies for detection. Multiple drugs can be detected simultaneously using SERS as long as their characteristic Raman peaks do not fully overlap with each other. To test the simultaneous detection of $\mathrm{MC}$ and 4-MMC, we measured the SERS spectra of three kinds of drug mixtures, including 5 ppm 4-MMC plus 1 ppm MC, 1 ppm 4-MMC plus 5 ppm MC, and 1 ppm 4-MMC plus 1 ppm MC. We also measured 1 ppm MC, 5 ppm MC, 1 ppm 4-MMC, and 5 ppm 4-MMC for comparison. The results, as shown in Figure 3, revealed that the SERS spectra of the mixtures had the characteristic Raman peaks of both drugs. It should be noted that, because the adsorption of one kind of molecule to the AgNPs could interfere with the adsorption of other molecules, the SERS spectra measured for the mixtures of MC and 4-MMC showed weaker characteristic Raman peaks than the SERS spectra of individual drugs of the same concentration. In addition, our results showed that the 4-MMC molecule appeared to have stronger adsorption to the AgNPs than the MC molecule because the intensities of its characteristic Raman peaks decreased less during the simultaneous detection of 4-MMC and MC. To determine the limits of detection during simultaneous detection, we performed SERS measurements of 4-MMC and MC of various concentrations. Figure $4 \mathrm{a}$ shows the SERS spectra of the mixtures of MC and 4-MMC, and Figure $4 \mathrm{~b}$ shows the relationships between the concentration of each drug in the mixture and the intensities of the characteristic Raman peaks. The results showed that, although the intensities of the characteristic Raman peaks of $\mathrm{MC}$ and 4-MMC were weaker when the two drugs were detected simultaneously, we could still detect both drugs at a concentration as low as $0.01 \mathrm{ppm}$ in the mixture.

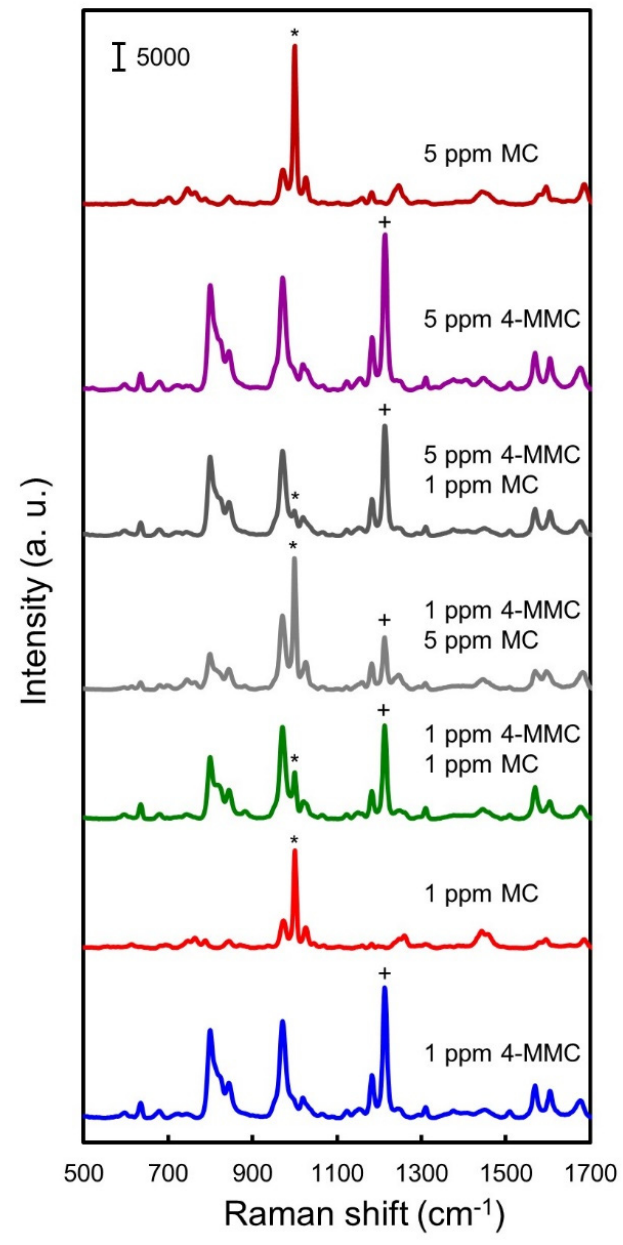

Figure 3. SERS detection of MC, 4-MMC, and mixtures of MC and 4-MMC in water. SERS spectra of 1 ppm MC, 5 ppm MC, 1 ppm 4-MMC, 5 ppm 4-MMC, 5 ppm 4-MMC plus 1 ppm MC, 1 ppm 4-MMC plus 5 ppm MC, and 1 ppm 4-MMC plus 1 ppm MC. The characteristic Raman peak of $\mathrm{MC}$ at $1000 \mathrm{~cm}^{-1}$ and the characteristic Raman peak of 4-MMC at $1212 \mathrm{~cm}^{-1}$ are marked with "*" and "+", respectively. 
(a)

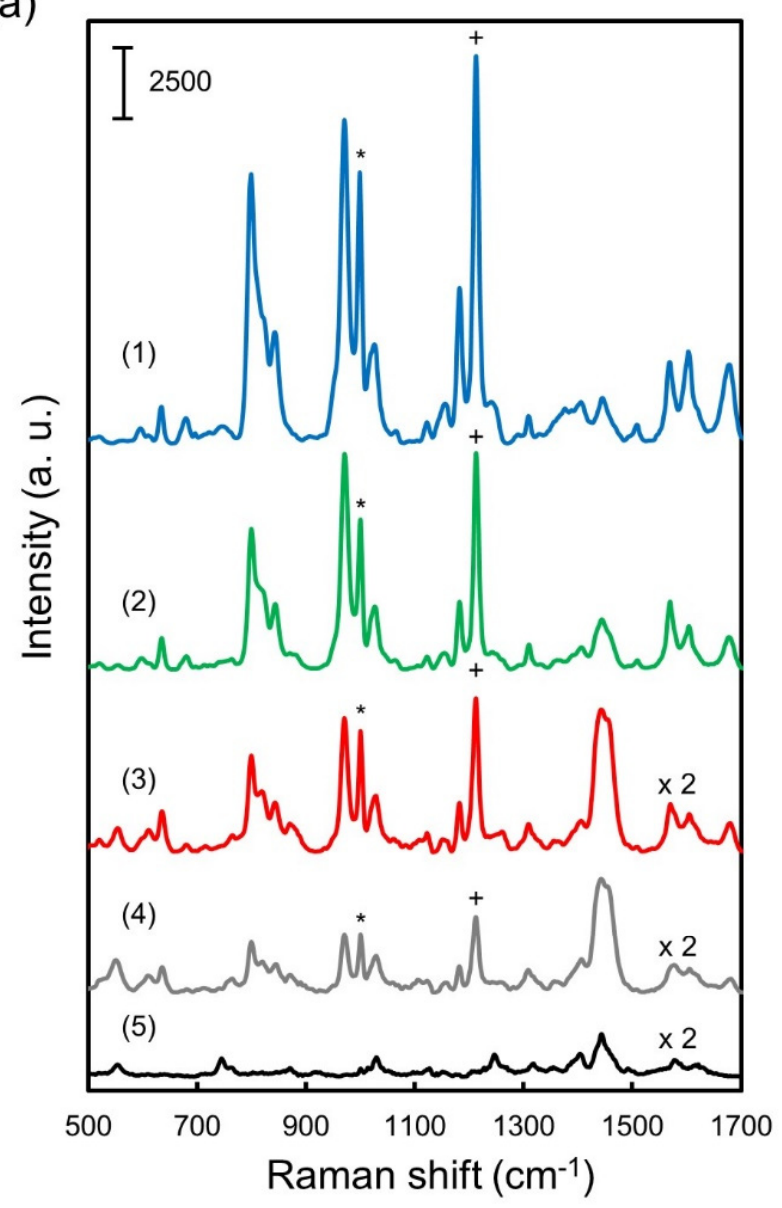

(b)

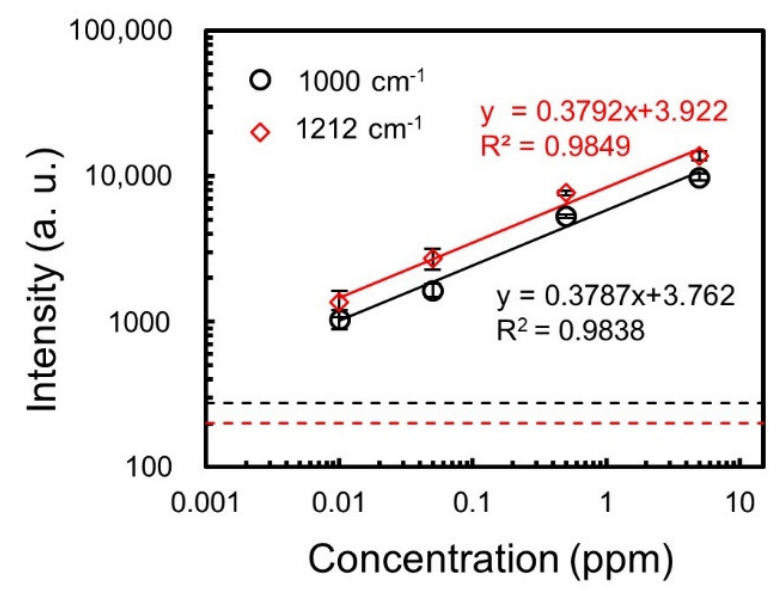

Figure 4. Simultaneous SERS detection of MC and 4-MMC in water. (a) SERS spectra of mixtures of MC and 4-MMC. The concentration of both MC and 4-MMC was 5, 0.5, 0.05, 0.01, and 0 ppm for the SERS spectrum (1), (2), (3), (4), and (5), respectively. The characteristic Raman peak of MC at $1000 \mathrm{~cm}^{-1}$ and the characteristic Raman peak of 4-MMC at $1212 \mathrm{~cm}^{-1}$ are marked with "** and “+”, respectively. (b) A plot of the intensity of the $1000 \mathrm{~cm}^{-1}$ peak versus MC concentration and the intensity of the $1212 \mathrm{~cm}^{-1}$ peak versus 4-MMC concentration. Error bars show standard deviations with $\mathrm{n}=30$. The straight lines are the linear regression lines, and the black and red dotted lines indicate mean plus $3 \sigma$ of the 1000 and the $1212 \mathrm{~cm}^{-1}$ peak, respectively, of the blank sample. 


\subsection{Urine Sample Pretreatment}

While we already demonstrated the sensitive detection of MC and 4-MMC standard solutions, to detect drugs in human urine samples, we had to use a suitable sample pretreatment method before the SERS measurements to reduce the interferences from other components in urine. As shown in Figure 5a, when using our SERS method to measure

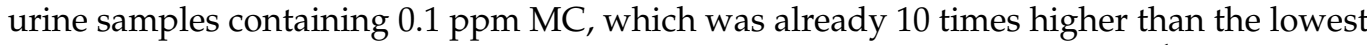
detected concentration shown in Figure 2a, we could not detect the $1000 \mathrm{~cm}^{-1}$ Raman peak of MC unless the urine samples were processed using the sample pretreatment method illustrated in Scheme 1. The results confirmed that using the sample pretreatment process to extract and concentrate drug molecules was essential for achieving sensitive detection of drugs in urine samples. Figure $5 \mathrm{~b}$ shows that, when the time duration for mixing hexane and the urine samples containing $0.1 \mathrm{ppm} \mathrm{MC} \mathrm{increased} \mathrm{from} 30 \mathrm{~s}$ to $3 \mathrm{~min}$ and $5 \mathrm{~min}$, the intensity of the characteristic Raman peak at $1000 \mathrm{~cm}^{-1}$ did not significantly increase with the mixing time. Therefore, to reduce the time of the sample pretreatment as much as possible, we only mixed hexane with urine samples for $30 \mathrm{~s}$ for latter experiments.

(a)

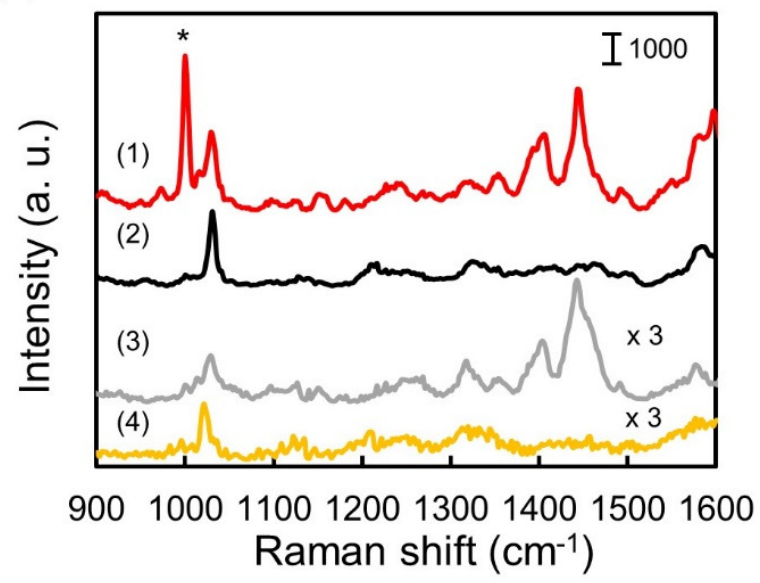

(b)

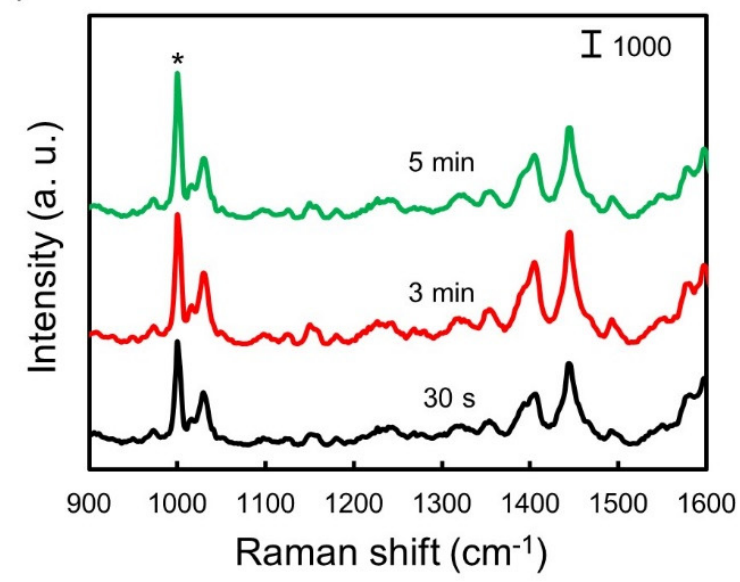

Figure 5. Effects of the sample pretreatment process on detection of drugs in urine. (a) SERS spectra of 0.1 ppm MC in urine measured (1) after and (2) before sample pretreatment and SERS spectra of blank urine samples measured (3) after and (4) before sample pretreatment. (b) SERS detection of $0.1 \mathrm{ppm} \mathrm{MC}$ in urine with different extraction time. The characteristic Raman peak of MC at $1000 \mathrm{~cm}^{-1}$ is marked with "*".

\subsection{Simultaneous Detection of $M C$ and 4-MMC in Urine}

We further tested the sample pretreatment method with standard solutions and urine samples containing drugs of different concentrations. We first prepared 1, 0.1, and 0.01 ppm MC standard solutions and processed them using the sample pretreatment method. Although these samples were not urine samples, we pretreated them before measuring their SERS spectra to understand how the detection results would be affected by the sample pretreatment process. As shown in Figure 6a, the results of the SERS measurements revealed that $0.01 \mathrm{ppm} \mathrm{MC}$ could still be detected after the sample pretreatment. Figure $6 \mathrm{~b}$ shows that the intensity of the $1000 \mathrm{~cm}^{-1}$ peak increased with the concentration of MC. Then, to test the detection of drugs in urine samples, we prepared urine samples containing $1,0.1$, and $0.01 \mathrm{ppm} \mathrm{MC}$ and then pretreated the samples using the same method before the SERS measurements. Figure 7a,b show that we could successfully detect MC in urine samples containing $0.01 \mathrm{ppm} \mathrm{MC} \mathrm{or} \mathrm{more.} \mathrm{The} \mathrm{relation} \mathrm{between} \mathrm{the} \mathrm{intensity} \mathrm{of} \mathrm{the}$ $1000 \mathrm{~cm}^{-1}$ peak and MC concentration shown in Figure $7 \mathrm{~b}$ was slightly different from that shown in Figure $6 \mathrm{~b}$ because they were measured with urine samples and with water samples, respectively. To understand the reproducibility of the SERS measurements, we prepared five urine samples containing $0.01 \mathrm{ppm} \mathrm{MC}$ and then performed 10 repeated 
measurements for each sample. Figure $7 \mathrm{c}$ shows the intensities of the $1000 \mathrm{~cm}^{-1}$ peak in the SERS spectra (Supplementary material Figure S4) of the five urine samples and the relative standard deviation (RSD) of the results, which was $13.3 \%$. Finally, we prepared urine samples containing both MC and 4-MMC to test the simultaneous extraction and detection of both drugs in urine. Figure $7 \mathrm{~d}$ shows that the SERS spectra of the extracted solutions presented the characteristic Raman peaks of both drugs, including the $1000 \mathrm{~cm}^{-1}$ peak of MC and the $1212 \mathrm{~cm}^{-1}$ peak of 4-MMC. The concentrations of MC and 4-MMC in the tested urine samples were in the range of $0.01-5 \mathrm{ppm}$. In contrast, the SERS spectra of the blank sample, which was the urine sample without drug additives, did not present the characteristic Raman peaks of the drugs. Figure 7e shows that the intensity of the 1000 and the $1212 \mathrm{~cm}^{-1}$ peak increased with the concentration of MC and 4-MMC.

(a)

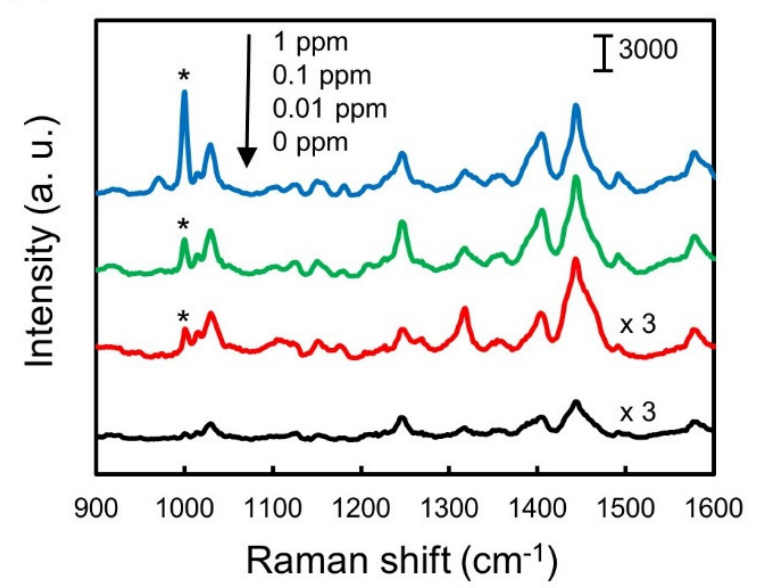

(b)

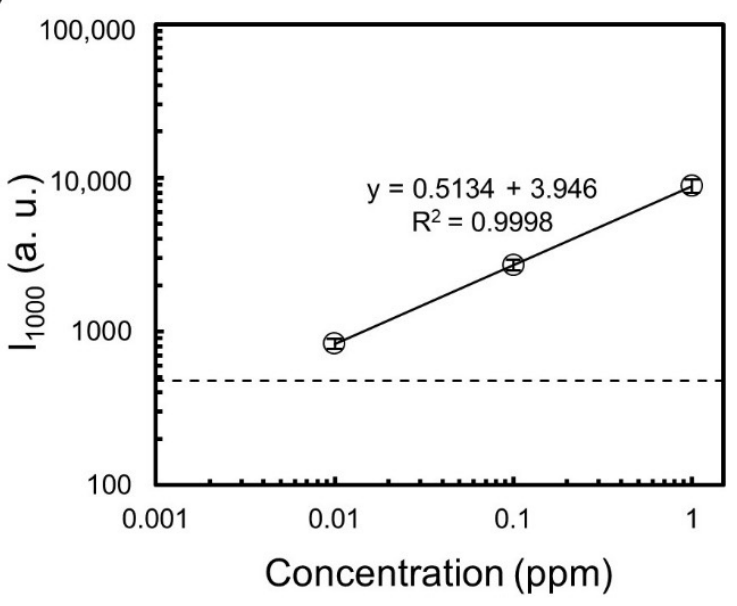

Figure 6. SERS detection of MC in water after sample pretreatment. (a) SERS spectra of MC in water measured after sample pretreatment. The characteristic Raman peak of MC at $1000 \mathrm{~cm}^{-1}$ is marked with "*”. (b) A plot of the intensity of the $1000 \mathrm{~cm}^{-1}$ peak versus MC concentration. Error bars show standard deviations with $n=30$. The straight line is the linear regression line, and the dotted line indicates mean plus $3 \sigma$ of the $1000 \mathrm{~cm}^{-1}$ peak of the blank sample.

Our results show that we could simultaneously detect MC and 4-MMC in urine at a concentration as low as $0.01 \mathrm{ppm}$. In comparison, Muhamadali et al. demonstrated the detection of 4-MMC in water and in urine with limits of detection of $\sim 800 \mathrm{ppm}$ by mixing AgNPs with sample solutions [35]. No sample pretreatment method was used in their study. Han et al. reported SERS detection of $10 \mathrm{ppm}$ MC and two other kinds of drugs in urine using self-assembled gold nanorod arrays, but they did not determine the limit of detection for MC [25]. Lee et al. showed that their polymer-stabilized Ag nanoparticle films could be used as SERS substrates to detect $5.7 \mu \mathrm{g}$ of MC using a swabbing method [34]. In addition to the SERS-based methods, an electrochemical method was used to detect 4-MMC with a limit of detection of $11.8 \mathrm{ppm}$ [46]. In comparison with these results, the SERS method developed in this study was one of the most sensitive rapid screening methods reported in the literature for the detection of MC and 4-MMC in urine. 
(a)

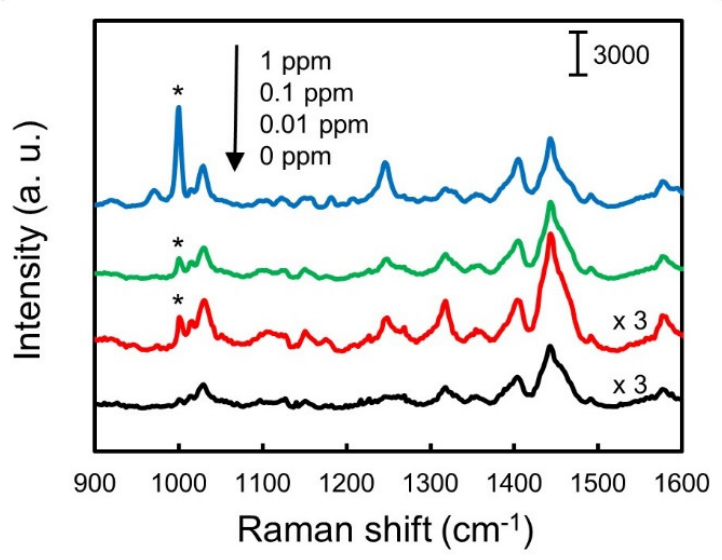

(c)

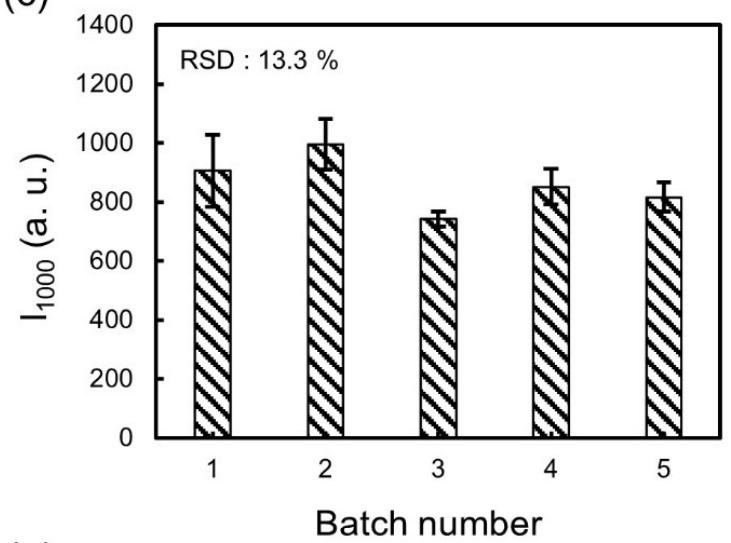

(e)

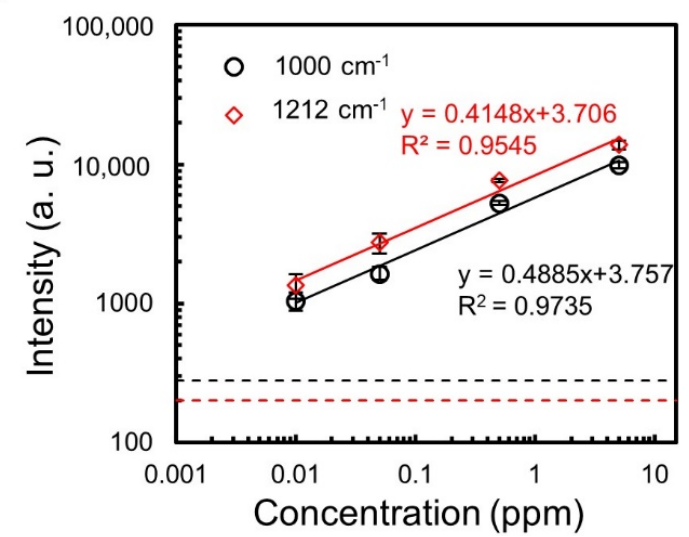

(b)

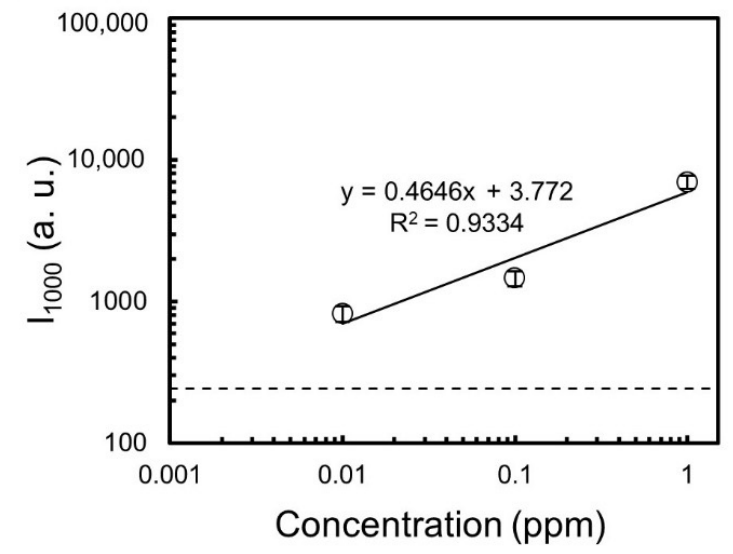

(d)

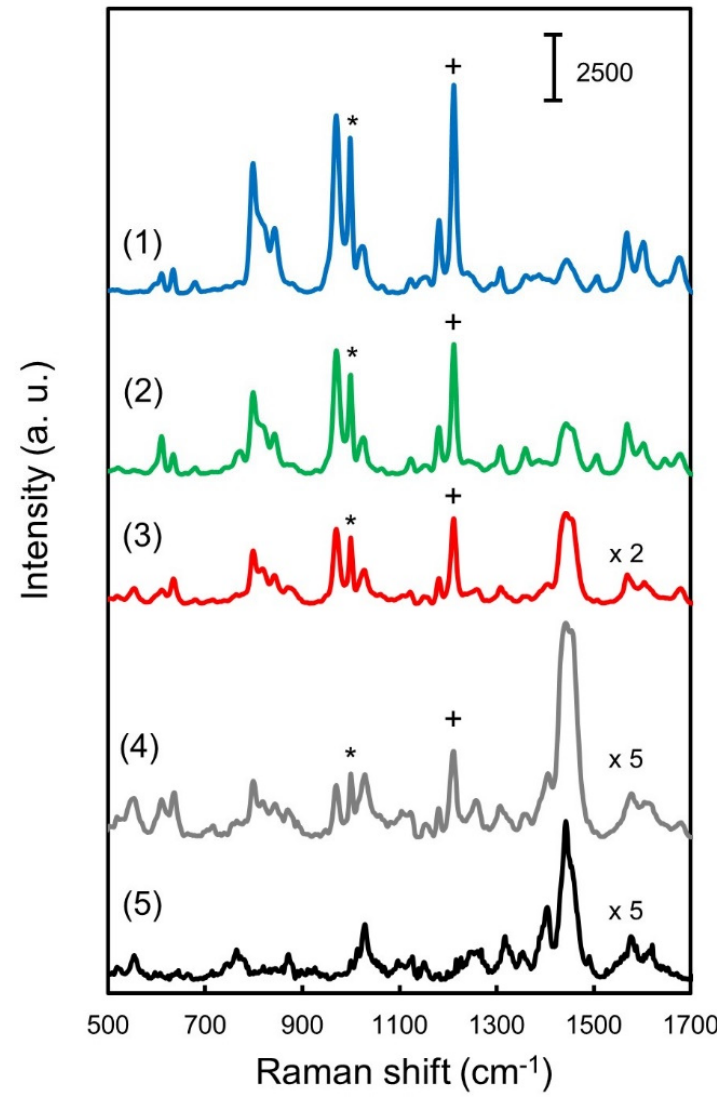

Figure 7. SERS detection of MC and 4-MMC in urine. (a) SERS spectra of MC in urine measured after sample pretreatment. The characteristic Raman peak of MC at $1000 \mathrm{~cm}^{-1}$ is marked with “*”. (b) A plot of the intensity of the $1000 \mathrm{~cm}^{-1}$ peak versus MC concentration. Error bars show standard deviations with $\mathrm{n}=30$. The straight line is the linear regression line, and the dotted line indicates mean plus $3 \sigma$ of the $1000 \mathrm{~cm}^{-1}$ peak of the blank sample. (c) The intensities of the 1000 $\mathrm{cm}^{-1}$ peak measured from 5 urine samples containing $0.01 \mathrm{ppm} \mathrm{MC}$. Error bars show standard deviations with $\mathrm{n}=10 .(\mathrm{d})$ SERS spectra of urine samples containing both MC and 4-MMC measured after sample pretreatment. The concentration of both MC and 4-MMC was 5, 0.5, 0.05, 0.01, and 0 ppm for the SERS spectrum (1), (2), (3), (4), and (5), respectively. The characteristic Raman peak of MC at $1000 \mathrm{~cm}^{-1}$ and the characteristic Raman peak of 4-MMC at $1212 \mathrm{~cm}^{-1}$ are marked with "*" and "+", respectively. (e) A plot of the intensity of the $t 1000 \mathrm{~cm}^{-1}$ peak versus MC concentration and the intensity of the $1212 \mathrm{~cm}^{-1}$ peak versus 4-MMC concentration. Error bars show standard deviations with $\mathrm{n}=10$. The straight lines are the linear regression lines, and the black and red dotted lines indicate mean plus $3 \sigma$ of the 1000 and the $1212 \mathrm{~cm}^{-1}$ peak, respectively, of the blank sample. 


\section{Conclusions}

In conclusion, we have successfully developed a rapid, low-cost, and sensitive method for the detection of MC and 4-MMC in urine. To reduce the interferences from other components in urine on the detection results, we used a simple sample pretreatment process that could extract and concentrate drugs from urine within 20 min before SERS measurements. To achieve the sensitive detection of drugs, we optimized the kind and concentration of the alkali halide salt used to quickly form Ag nanoclusters with strong SERS effects. Our results showed that, by using $\mathrm{NaBr}$ as the aggregating agents for AgNPs, we could simultaneously detect both MC and 4-MMC in urine at a concentration as low as $0.01 \mathrm{ppm}$ after sample pretreatment. The whole measurement process could be finished within 1 min because we measured the SERS spectra immediately after we added the AgNPs and $\mathrm{NaBr}$ to the extracted sample solution without incubation. We believe that the SERS-based detection method and the sample pretreatment process developed in this study have a great potential to be used for rapid screening of illegal drugs in urine.

Supplementary Materials: The following are available online at https: / www.mdpi.com/article/ 10.3390/nano11071789/s1, Figure S1: Extinction spectra and TEM image of the AgNPs, Figure S2: Hydrodynamic diameter of the AgNPs determined using dynamic light scattering (DLS), Figure S3: Time-lapse observation of SERS spectra after the addition of NaBr. Figure S4: SERS spectra of 5 urine samples containing $0.01 \mathrm{ppm} \mathrm{MC}$.

Author Contributions: Conceptualization, Y.-C.C., and Y.-F.C.; methodology, Y.-F.C.; investigation and data curation, Y.-C.C., S.-W.H., and H.-H.W.; writing-original draft, Y.-C.C.; writing-review and editing, Y.-L.W., and Y.-F.C.; supervision, Y.-L.W., and Y.-F.C.; funding acquisition, Y.-L.W., and Y.-F.C. All authors have read and agreed to the published version of the manuscript.

Funding: This work was supported by the Ministry of Science and Technology, Taiwan (MOST 107-2622-E-010-002-CC2, MOST 108-2628-E-010-001-MY3) and Taiwan Advance Bio-Pharmaceutical Inc.

Data Availability Statement: The data presented in this study are available on request from the corresponding author.

Conflicts of Interest: This work was financially supported in part by Taiwan Advance Bio-Pharmaceutical Inc.

\section{References}

1. Feng, J.; Wang, L.; Dai, I.; Harmon, T.; Bernert, J.T. Simultaneous determination of multiple drugs of abuse and relevant metabolites in urine by LC-MS-MS. J. Anal. Toxicol. 2007, 31, 359-368. [CrossRef]

2. Wang, J.M.; Yang, Z.; Lechago, J. Rapid and simultaneous determination of multiple classes of abused drugs and metabolites in human urine by a robust LC-MS/MS method-Application to urine drug testing in pain clinics. Biomed. Chromatogr. 2013, 27, 1463-1480. [CrossRef]

3. Fiorentin, T.R.; Fogarty, M.; Limberger, R.P.; Logan, B.K. Determination of cutting agents in seized cocaine samples using GC-MS, GC-TMS and LC-MS/MS. Forensic Sci. Int. 2019, 295, 199-206. [CrossRef]

4. Saitman, A.; Park, H.D.; Fitzgerald, R.L. False-positive interferences of common urine drug screen immunoassays: A review. J. Anal. Toxicol. 2014, 38, 387-396. [CrossRef]

5. Angelini, D.J.; Biggs, T.D.; Prugh, A.M.; Smith, J.A.; Hanburger, J.A.; Llano, B.; Avelar, R.; Ellis, A.; Lusk, B.; Naanaa, A.; et al. Detection of fentanyl and derivatives using a lateral flow immunoassay. Forensic Chem. 2021, 23, 100309. [CrossRef]

6. Ruperez, A.; Montes, R.; Laserna, J.J. Identification of stimulant-drugs by surface-enhanced Raman-spectrometry on colloidal silver. Vib. Spectrosc 1991, 2, 145-154. [CrossRef]

7. Guerrini, L.; Garcia-Ramos, J.V.; Domingo, C.; Sanchez-Cortes, S. Sensing polycyclic aromatic hydrocarbons with dithiocarbamatefunctionalized Ag nanoparticles by surface-enhanced Raman scattering. Anal. Chem. 2009, 81, 953-960. [CrossRef] [PubMed]

8. Wu, L.-A.; Li, W.-E.; Lin, D.-Z.; Chen, Y.-F. Three-dimensional SERS substrates formed with plasmonic core-satellite nanostructures. Sci. Rep. 2017, 7, 13066. [CrossRef] [PubMed]

9. Dugandzic, V.; Kupfer, S.; Jahn, M.; Henkel, T.; Weber, K.; Cialla-May, D.; Popp, J. A SERS-based molecular sensor for selective detection and quantification of copper(II) ions. Sens. Actuators B-Chem. 2019, 279, 230-237. [CrossRef]

10. D'Agostino, A.; Giovannozzi, A.M.; Mandrile, L.; Sacco, A.; Rossi, A.M.; Taglietti, A. In situ seed-growth synthesis of silver nanoplates on glass for the detection of food contaminants by surface enhanced Raman scattering. Talanta 2020, $216,120936$. [CrossRef] 
11. Deriu, C.; Conticello, I.; Mebel, A.M.; McCord, B. Micro solid phase extraction surface-enhanced Raman spectroscopy ( $\mu$ SPE/SERS) screening test for the detection of the synthetic cannabinoid JWH-018 in oral fluid. Anal. Chem. 2019, 91, 4780-4789. [CrossRef]

12. Li, Y.; Zeng, Y.; Mao, Y.; Lei, C.; Zhang, S. Proximity-dependent isothermal cycle amplification for small-molecule detection based on surface enhanced Raman scattering. Biosens. Bioelectron. 2014, 51, 304-309. [CrossRef]

13. Kline, N.D.; Tripathi, A.; Mirsafavi, R.; Pardoe, I.; Moskovits, M.; Meinhart, C.; Guicheteau, J.A.; Christesen, S.D.; Fountain, A.W. Optimization of surface-enhanced Raman spectroscopy conditions for implementation into a microfluidic device for drug detection. Anal. Chem. 2016, 88, 10513-10522. [CrossRef] [PubMed]

14. Meng, J.; Tang, X.H.; Zhou, B.B.; Xie, Q.W.; Yang, L.B. Designing of ordered two-dimensional gold nanoparticles film for cocaine detection in human urine using surface-enhanced Raman spectroscopy. Talanta 2017, 164, 693-699. [CrossRef]

15. Kong, X.; Chong, X.; Squire, K.; Wang, A.X. Microfluidic diatomite analytical devices for illicit drug sensing with ppb-Level sensitivity. Sens. Actuators B-Chem. 2018, 259, 587-595. [CrossRef]

16. Ameku, W.A.; Gonçalves, J.M.; Ataide, V.N.; Ferreira Santos, M.S.; Gutz, I.G.R.; Araki, K.; Paixão, T.R.L.C. Combined colorimetric and electrochemical measurement paper-based device for chemometric proof-of-concept analysis of cocaine samples. ACS Omega 2021, 6, 594-605. [CrossRef] [PubMed]

17. Masterson, A.N.; Hati, S.; Ren, G.; Liyanage, T.; Manicke, N.E.; Goodpaster, J.V.; Sardar, R. Enhancing nonfouling and sensitivity of surface-enhanced Raman scattering substrates for potent plasma via fabrication of a flexible plasmonic patch. Anal. Chem. 2021, 93, 2578-2588. [CrossRef] [PubMed]

18. Segawa, H.; Fukuoka, T.; Itoh, T.; Imai, Y.; Iwata, Y.T.; Yamamuro, T.; Kuwayama, K.; Tsujikawa, K.; Kanamori, T.; Inoue, H. Rapid detection of hypnotics using surface-enhanced Raman scattering based on gold nanoparticle co-aggregation in a wet system. Analyst 2019, 144, 2158-2165. [CrossRef] [PubMed]

19. Yan, X.; Li, P.; Zhou, B.; Tang, X.; Li, X.; Weng, S.; Yang, L.; Liu, J. Optimal hotspots of dynamic surfaced-enhanced Raman spectroscopy for drugs quantitative detection. Anal. Chem. 2017, 89, 4875-4881. [CrossRef] [PubMed]

20. Dies, H.; Raveendran, J.; Escobedo, C.; Docoslis, A. Rapid identification and quantification of illicit drugs on nanodendritic surface-enhanced Raman scattering substrates. Sens. Actuators B-Chem. 2018, 257, 382-388. [CrossRef]

21. Yang, Y.; Li, Z.-Y.; Yamaguchi, K.; Tanemura, M.; Huang, Z.; Jiang, D.; Chen, Y.; Zhou, F.; Nogami, M. Controlled fabrication of silver nanoneedles array for SERS and their application in rapid detection of narcotics. Nanoscale 2012, 4, 2663-2669. [CrossRef]

22. Yu, B.; Cao, C.; Li, P.; Mao, M.; Xie, Q.; Yang, L. Sensitive and simple determination of zwitterionic morphine in human urine based on liquid-liquid micro-extraction coupled with surface-enhanced Raman spectroscopy. Talanta 2018, 186, 427-432. [CrossRef]

23. Wang, C.; Xu, X.; Qiu, G.; Ye, W.; Li, Y.; Harris, R.A.; Jiang, C. Group-targeting SERS screening of total benzodiazepines based on large-size (111) faceted silver nanosheets decorated with zinc oxide nanoparticles. Anal. Chem. 2021, 93, 3403-3410. [CrossRef] [PubMed]

24. Andreou, C.; Hoonejani, M.R.; Barmi, M.R.; Moskovits, M.; Meinhart, C.D. Rapid detection of drugs of abuse in saliva using surface enhanced Raman spectroscopy and microfluidics. ACS Nano 2013, 7, 7157-7164. [CrossRef]

25. Han, Z.Z.; Liu, H.L.; Meng, J.; Yang, L.B.; Liu, J.; Liu, J.H. Portable kit for identification and detection of drugs in human urine using surface-enhanced Raman spectroscopy. Anal. Chem. 2015, 87, 9500-9506. [CrossRef] [PubMed]

26. Dong, R.; Weng, S.; Yang, L.; Liu, J. Detection and direct readout of drugs in human urine using dynamic surface-enhanced Raman spectroscopy and support vector machines. Anal. Chem. 2015, 87, 2937-2944. [CrossRef]

27. Han, Z.; Liu, H.; Wang, B.; Weng, S.; Yang, L.; Liu, J. Three-dimensional surface-enhanced Raman scattering hotspots in spherical colloidal superstructure for identification and detection of drugs in human urine. Anal. Chem. 2015, 87, 4821-4828. [CrossRef]

28. Ma, Y.; Liu, H.; Mao, M.; Meng, J.; Yang, L.; Liu, J. Surface-enhanced Raman spectroscopy on liquid interfacial nanoparticle arrays for multiplex detecting drugs in urine. Anal. Chem. 2016, 88, 8145-8151. [CrossRef]

29. Nuntawong, N.; Eiamchai, P.; Somrang, W.; Denchitcharoen, S.; Limwichean, S.; Horprathum, M.; Patthanasettakul, V.; Chaiya, S.; Leelapojanaporn, A.; Saiseng, S. Detection of methamphetamine/amphetamine in human urine based on surface-enhanced Raman spectroscopy and acidulation treatments. Sens. Actuators B-Chem. 2017, 239, 139-146. [CrossRef]

30. Fang, W.; Zhang, B.; Han, F.Y.; Qin, Z.N.; Feng, Y.Q.; Hu, J.M.; Shen, A.G. On-site and quantitative detection of trace methamphetamine in urine/serum samples with a surface-enhanced Raman scattering-active microcavity and rapid pretreatment device. Anal. Chem. 2020, 92, 13539-13549. [CrossRef] [PubMed]

31. Faulds, K.; Smith, W.E.; Graham, D.; Lacey, R.J. Assessment of silver and gold substrates for the detection of amphetamine sulfate by surface enhanced Raman scattering (SERS). Analyst 2002, 127, 282-286. [CrossRef]

32. Turzhitsky, V.; Zhang, L.; Horowitz, G.L.; Vitkin, E.; Khan, U.; Zakharov, Y.; Qiu, L.; Itzkan, I.; Perelman, L.T. Picoanalysis of drugs in biofluids with quantitative label-free surface-enhanced Raman spectroscopy. Small 2018, 14, 1802392. [CrossRef] [PubMed]

33. Stewart, A.; Bell, S.E.J. Modification of Ag nanoparticles with mixed thiols for improved SERS detection of poorly adsorbing target molecules: Detection of MDMA. Chem. Commun. 2011, 47, 4523-4525. [CrossRef] [PubMed]

34. Lee, W.W.Y.; Silverson, V.A.D.; Jones, L.E.; Ho, Y.C.; Fletcher, N.C.; McNaul, M.; Peters, K.L.; Speers, S.J.; Bell, S.E.J. Surfaceenhanced Raman spectroscopy of novel psychoactive substances using polymer-stabilized Ag nanoparticle aggregates. Chem. Commun. 2016, 52, 493-496. [CrossRef] [PubMed] 
35. Muhamadali, H.; Watt, A.; Xu, Y.; Chisanga, M.; Subaihi, A.; Jones, C.; Ellis, D.I.; Sutcliffe, O.B.; Goodacre, R. Rapid detection and quantification of novel psychoactive substances (NPS) using Raman spectroscopy and surface-enhanced Raman scattering. Front. Chem. 2019, 7, 412. [CrossRef] [PubMed]

36. Farquharson, S.; Lee, Y.H. Trace drug analysis by surface-enhanced Raman spectroscopy. Proc. SPIE 2000, 4200, 89-95.

37. Sutherland, W.S.; Laserna, J.J.; Angebranndt, M.J.; Winefordner, J.D. Surface-enhanced Raman analysis of sulfa drugs on colloidal silver dispersion. Anal. Chem. 1990, 62, 689-693. [CrossRef] [PubMed]

38. Liu, H.L.; Yang, L.B.; Liu, J.H. Three-dimensional SERS hot spots for chemical sensing: Towards developing a practical analyzer. TrAC-Trends Anal. Chem. 2016, 80, 364-372. [CrossRef]

39. Zhang, Q.; Lee, Y.H.; Phang, I.Y.; Lee, C.K.; Ling, X.Y. Hierarchical 3D SERS substrates fabricated by integrating photolithographic microstructures and self-assembly of silver nanoparticles. Small 2014, 10, 2703-2711. [CrossRef]

40. Liu, H.L.; Yang, Z.L.; Meng, L.Y.; Sun, Y.D.; Wang, J.; Yang, L.B.; Liu, J.H.; Tian, Z.Q. Three-dimensional and time-ordered surface-enhanced Raman scattering hotspot matrix. J. Am. Chem. Soc. 2014, 136, 5332-5341. [CrossRef]

41. Wang, H.Y.; Fang, J.M.; Xu, J.F.; Wang, F.; Sun, B.; He, S.N.; Sun, G.P.; Liu, H.L. A hanging plasmonic droplet: Three-dimensional SERS hotspots for a highly sensitive multiplex detection of amino acids. Analyst 2015, 140, 2973-2978. [CrossRef] [PubMed]

42. Sun, Y.D.; Han, Z.Z.; Liu, H.L.; He, S.N.; Yang, L.B.; Liu, J.H. Three-dimensional hotspots in evaporating nanoparticle sols for ultrahigh Raman scattering: Solid-liquid interface effects. Nanoscale 2015, 7, 6619-6626. [CrossRef] [PubMed]

43. Wang, Y.K.; Wei, Z.Y.; Zhang, Y.; Chen, Y.F. Glycerol-assisted construction of long-life three-dimensional surface-enhanced Raman scattering hot spot matrix. Langmuir 2019, 35, 15795-15804. [CrossRef] [PubMed]

44. Panigrahi, S.; Praharaj, S.; Basu, S.; Ghosh, S.K.; Jana, S.; Pande, S.; Vo-Dinh, T.; Jiang, H.; Pal, T. Self-assembly of silver nanoparticles: Synthesis, stabilization, optical properties, and application in surface-enhanced Raman scattering. J. Phys. Chem. B 2006, 110, 13436-13444. [CrossRef] [PubMed]

45. Koo, T.W.; Chan, S.; Sun, L.; Su, X.; Zhang, J.W.; Berlin, A.A. Specific chemical effects on surface-enhanced Raman spectroscopy for ultra-sensitive detection of biological molecules. Appl. Spectrosc. 2004, 58, 1401-1407. [CrossRef]

46. Smith, J.P.; Metters, J.P.; Khreit, O.I.G.; Sutcliffe, O.B.; Banks, C.E. Forensic electrochemistry applied to the sensing of new psychoactive substances: Electroanalytical sensing of synthetic cathinones and analytical validation in the quantification of seized street samples. Anal. Chem. 2014, 86, 9985-9992. [CrossRef] 